Infusionsther Transfusionsmed 1994;21:289

\title{
Impressum, Vol. 21, No. 5, 1994
}

Offizielles Organ

der Deutschen Geselischaft für Transfusionsmedizin

und Immunhämatologie

Gründungsherausgeber

H. Reissigl, Innsbruck

Herausgeber

J. Eckart, Augsburg V. Kretschmer, Marburg K. Meßmer, München K. Peter, München W.

Stangel, Hannover K.-H. Usadel, Frankfurt

Schriftleiter

H. Forst, München

Assistent des Schriftleiters

B. Zwißler, München

Wissenschaftlicher Beirat

M. Adolph, Augsburg

F.W. Ahnefeld, Ulm

J. Askanazi, New York

C. Baldamus, Köln

H. Bardenheuer, Heidelberg

J.-F. Baron, Paris

K.-H. Bäßler, Mainz

W. Behrendt, Aachen

H. Borberg, Köln

U. B. Bruckner, Ulm

W. Dick, Mainz

J. Eckart, Augsburg

R. Eckstein, Erlangen

A. Encke, Frankfurt

K. Falke, Berlin

U. Finsterer, München

H. Forst, München

L. Frey, München

Y. Fujita, Okayama

L. Gattinoni, Mailand

M. Georgieff, Ulm

A. Grünert, Ulm

H. J. Gurland, München

P. Hanfland, Bonn

M. Heberer, Basel

J. P. Isbister, Sydney 

K. Jauch, München
W.-P Kloevekorn, Bad Nauheim
E. Kolb, München
W. Kox, Berlin
G. C. Kramer, Galveston
H. G. Kress, Wien
V. Kretschmer, Marburg
B. Kubanek, UlmP. Kühnl, Hamburg
H. Laubenthal, Bochum W. Mempel, München K. Meßmer, München N. Mutz, Innsbruck U E. Nydegger, Bern W. Oettinger, Trier K. Peter, München

Th. Prien, Münster H. Reissigl, Innsbruck D. Roelcke, Heidelberg R. Roos, München W.

Schleinzer, Hamburg

D. Schönitzer, InnsbruckH.-P. Schuster, HildesheimH.-G. Sieberth, AachenR.A.K. Stahl, HamburgW. Stangel, Hannover

U. Suchner, München

L. Sunder-Plassmann, Ulm

K.-H. Usadel, Frankfurt

E. Wenzel, Homburg/SaarK. Werdan, München

K. Widhalm, Wien G. Wolfram, München R. Zander, Mainz B. Zwißler, München

Die Zeitschrift erscheint zweimonatlich; pro Jahr erscheint 1 Band zu je 6 Heften.

DGTI-Mitglieder erhalten die Zeitschrift im Rahmen ihrer Mitgliedschaft. Bezugspreis für Jahrgang 21, 1994: DM 168,- I öS 1310- I SFr 132,-. 1 Einzelheft kostet DM 30-/öS 234-/SFr 25,-, einschließlich MwSt., zuzüglich Postge-bühren. Der Abonnementpreis ist im voraus zahlbar. Das Abonnement der Zeitschrift läuft weiter, wenn es nicht spätestens 4 Wochen vor Abschluß eines Bandes abbestellt wird. Abonnementbestellungen können bei jeder Buchhandlung oder direkt beim Verlag aufgegeben werden:

Bundesrepublik Deutschland: S. Karger GmbH, Lörracher Str. 16 a, D-79115 Freiburg, Tel. (0761) 452070, Fax (0761) 4520714, Postgiro München 61440-808. Übrige Lander: S. Karger AG, Allschwilerstr. 10, Postfach, CH-4009 Basel, Telefon (0 61) 3061111 , Telex 62652 CH, Telefax (0 61) 30612 34. Anzeigen:

S. Karger Verlag für Medizin und Naturwissenschaften GmbH, Lörracher Str. 16 a, D-79115 Freiburg, Tel. (07 61) 45 2070. Gültig ist die Preisliste Nr. 11 vom 1. Januar 1994.

Für den Inhalt außerhalb des redaktionellen Teiles (insbesondere Anzeigen, Industrieinformationen, Pressezitate und Kongreßinformationen) übernehmen Schriftleitung, Beirat und Verlag keine Gewähr.

Eine Markenbezeichnung kann warenzeichenrechtlich geschützt sein, auch wenn bei ihrer Verwendung in dieser Zeitschrift das Zeichen ${ }^{\circledR}$ oder ein anderer Hinweis auf etwa bestehende Schutzrechte fehlen sollte. Für Satzfehler, insbesondere bei Dosierungsangaben, wird keine Gewähr übernommen.

Die Zeitschrift sowie alle in ihr enthaltenen einzelnen Beiträge und Abbildungen sind urheberrechtlich geschützt. Jede Verwertung, die nicht ausdrücklich vom Ur-heberrechtsgesetz zugelassen ist, bedarf der vorherigen Zustimmung des Verlags. Das gilt insbesondere für Vervielfältigungen, Bearbeitungen, Übersetzungen, Mi-kroverfilmungen und die Einspeicherung und Verarbeitung in elektronischen Sy-stemen. Fotokopien dürfen nur für den persönlichen Gebrauch als Einzelkopien hergestellt werden. Jede im Bereich eines gewerblichen 
Unternehmens zulässig hergestellte oder benutzte Kopie dient gewerblichen Zwecken gem. § 54(2) UrhG und verpflichtet zur Gebührenzahlung an die Verwertungsgesellschaft WORT, Abt. VG Wissenschaft, Goethestraße 49, D-80336 München.

(C) Copyright 1994 by S. Karger

Verlag für Medizin und Naturwissenschaften GmbH

Lörracher Str. 16 a, D-79115 Freiburg

Verlagsleitung: Steven Karger

Presserechtlich verantwortlich: Georg Brunner

Redaktionsassistenz: Martina Zeller

Anzeigenverwaltung: Christiane Opitz

Satz und Druck: Walter Biering GmbH

Grafischer Betrieb

Freisinger Landstraße 21

D-80939 München 